\title{
E-Learning and Personalized L earning Path: A Proposal Based on the A daptive Educational Hypermedia System
}

\author{
http://dx.doi.org/10.3991/ijet.v9i2.3211 \\ F. Colace, M. De Santo and L. Greco \\ DIEM - University of Salerno, Fisciano (Salerno), Italy
}

\begin{abstract}
The E-L earning is becoming an effective approach for the improving of quality of learning. M any institutions are adopting this approach both to improve their traditional courses both to increase the potential audience. In the last period great attention is paid in the introduction of methodologies and techniques for the adaptation of learning process to the real needs of students. In this scenario the A daptive E ducational Hypermedia System can be an effective approach. Adaptive hypermedia is a promising area of research at the crossroads of hypermedia and adaptive systems. One of the most important fields where this approach can be applied is just the e-Learning. In this context the adaptive learning resources selection and sequencing is recognized as among one of the most interesting research questions. An Adaptive Educational Hypermedia System is composed by services for the management of the Knowledge Space, the definition of a User Model, the observation of student during his learning period and, as previously said, the adaptation of the learning path according to the real needs of the students. In particular the use of ontology's formalism for the modeling of the "knowledge space" related to the course can increase the sharable of learning objects among similar courses or better contextualize their role in the course. This paper addresses the design problem of an A daptive hypermedia system by the definition of methodologies able to manage each its components, In particular an original user, learning contents, tracking strategies and adaptation model are developed. The proposed Adaptive E ducational Hypermedia System has been integrated in an eL earning platform and an experimental campaign has been conducted. In particular the proposed approach has been introduced in three different blended courses. A comparison with traditional approach has been described and the obtained results seem to be very promising.
\end{abstract}

Index Terms- e-L earning, Adaptive Educative Hypermedia System, Computer-A ssisted Education, Assessment

\section{INTRODUCTION}

Often classrooms are composed by students inattentive or at least bored and wondered. So the question for the teacher is: why I am not able to reach these students, why they are not excited about the material also if it is presented in an organized and coherent manner. This sense of frustration increases when he faces the poor students' performance on tests. On the other hand students can drop out or be hostile about the classroom environment while teacher could become over critical of them starting to question about students' capabilities and to turn the class- room into "him against them". The reason of these difficulties, maybe, can be in the way of teaching that does not match the way the majority of students in the classroom process information and learn new things. In other words the classroom environment could be incompatible with the students' preferred learning style resulting in stress, frustration and even burnout. There is substantial evidence that students learn in a variety of ways and that traditional teaching addresses only a small subset of the learning styles that are in a classroom. A s consequence many valuable students lose interest and get low grades in classes, change field and in some cases drop out of school altogether. In order to change this situation a good solution could be a blended approach. In other words the traditional lectures have to be supported by adapted distance learning services. In this way the e-Learning environments should not only be limited to transfer didactic units to the student but also to support a new concept of "teaching" whose final aim is to increase the quality and effectiveness of the traditional teaching. This approach can be effective and overcome some problems related to the use of the eL earning: in fact one of the main criticisms to e-L earning approach is in its lack of interaction between teachers and students. In this way, teachers have a poor control on the students' progresses and attitudes during their learning process. On the other hand, the e-L earning platforms can collect a large size of data concerning the student's learning process but this huge quantity of information often can bewilder teachers that evaluate the student's learning trend by the use of few information: in general the student's results at the final or end-unit tests and the time that they spent on the various learning object. Obviously, this information can not explain all the aspects of student's knowledge process and teachers can not support effectively them. In this scenario an interesting contribute can be furnished by the use of A daptive Educational Hypermedia System and its main components. An Adaptive Educational Hypermedia System is an alternative to the traditional "one-size-fits-all" and builds a model of the goals, preferences and knowledge of each individual user, and use this model throughout the interaction with the user, in order to adapt to the needs of that user. In particular in the case of e-L earning a student by the use of an adaptive educational hypermedia system can access to contents adapted specifically to his or her knowledge of the subject. In particular an A daptive Educational Hypermedia System is defined by the introduction of four main components: the K nowledge Space, the User M odel, the Observations Model and the Adaptation Model [1]. A daptive Educational Hypermedia Systems have been used as effective 
approaches to address this dissatisfaction by attempting to personalize the learning experience for the learner. $\mathrm{Nu}$ merous adaptive hypermedia systems have been implemented over the last fifteen years and these systems can be characterized as first generation, second generation and third generation based on when they were developed and what delivery mechanism was used for deployment of the systems [2]. The first generation systems are adaptive systems that were not distributed in nature. In particular they provide a limited adaptability through stereotype based user models and limited functionality adaptation techniques such as conditional text filters, direct guidance, hiding and primitive link annotation [3][4][5]. The advent of World Wide W eb provided new opportunities for the development of adaptive hypermedia systems and led them the second generation. The second generation of Adaptive Hypermedia Educational Systems uses the W W W as delivery and presentation means. These systems are platform independent and introduce new capabilities as adaptive multimedia presentation, map adaptation and link sorting. These systems provided a better definition of the adaptation techniques in order to provide greater functionality. In the same time user models became more efficient and incorporated more user characteristics [6][7]. The third generation of A daptive Hypermedia Educational System removes the problem of the adaptation through one-dimensional, stereotypical user models. These systems incorporate multiple dimensions of the user including expertise, user goals, interests and preferred learning style by subject matter. The third generation of A daptive Hypermedia Educational Systems provides a fine degree of adaptation granularity and adapts more than just hypertext, introducing fine grained multimedia adaptation. As previously said the Adaptive Educational Hypermedia Systems are gaining importance in the last period above all in the e-Learning field. In literature many papers deal with this argument and offer several models of Adaptive Educative Hypermedia System whose target is the identification of the main parameters to track and characterize the user in an e-Learning process [8]. Some of them are based on the formalism of the graphs where the nodes estimate the student's knowledge [9]. Other approaches focus their attention on the actions of the student during the learning process furnishing a detailed report to the tutor [10][11][12][18]. A nother interesting approach is in [13]. This paper describes a model that builds the best students' learning path starting from the analysis of some features outlining their main pedagogical characteristics. This approach is student-centered and students' parameters are selected according to three main factors: the test performance, the time performance, and the reviewed topics. The above factors, by the use of an opportune mathematical model, indicates to teachers the learning level achieved by students. By the analysis of these indexes moreover, it is possible to establish if students can attend the next lesson of the course or need more support in this part of the learning phase. The previous described approach is the scenario where this paper is set. In fact the real aim of this paper is the design of an adaptive educational hypermedia system by the definition of its main components. In particular an original tracking strategy for the student's monitoring status during the learning period is developed and at this aim some indexes able to describe the students' attitude have been introduced. In this way the proposed A daptive Educational Hypermedia System can easily update the user profile, expressed by the use of a model based on IMS LIP metadata standard, and adapt the distance learning path. At the same time a detailed report on students' activities and their main difficulties has sent to the teacher, underlining the main criticisms for each student. The paper has the following organization: first of all a brief description of A daptive Hypermedia System is introduced and a more detailed discussion on the student's tracking question is faced. Then the various indexes and the tracking approach are described. So the approach used to build the best learning path is analyzed. In the last section of the paper some experimental results are showed.

\section{AdAPTIVE HYPERMEDIA SYSTEM : A PROPOSAL}

A n A daptive Educational Hypermedia System (AEHS) [14][15] is a general framework which aims to personalize, optimize and enforce the student's learning experience by the use of services based on ICT. A ccording to a general definition, reflecting the current state of- the-art, an AEHS is composed by four main components:

- The Knowledge Space (KS): this component aims to describe and manage the courses' knowledge domains. U sually this component is subdivided into two sub-components: the first one is the Media Space. This module introduces services for the management of the educational resources by the use of descriptive information (e.g. metadata attributes, usage attributes etc.). The second sub-module is the Domain Model. It aims to describe the knowledge domain in hand by the use of graphical formalisms able to represent the topics, their relations and learning goals. In this scenario the use of the ontology formalism is an effective way to face the problem

- The User M odel (UM): this component has the aim to describe information and data about an individual learner such as knowledge status and learning style preferences. The User Model contains two submodels: the first one, namely the L earner K nowledge Space, represents the learners' state of knowledge on a topic while the second one, namely the Learner's Cognitive Characteristics and learning preferences, has the aim to represent the learners' cognitive characteristics and learning preferences. This distinction is needed because the Learner K nowledge Space has to be frequently updated during the interactions between learners and learning objects. On the other hand, the learner's cognitive characteristics and learning preferences has a slower evolution

- The A daptation M odel (AM): this component contains the rules for the description of the runtime behaviour of the AEHS. The rules are usually divided in: Concept Selection Rules and the Content Selection Rules. The first ones select the learner's appropriate concepts from the Domain Model to be covered while the second ones are used for the selection of appropriate resources from the M edia Space. In these rule sets the pedagogic and didactic approach of the AEHS is in.

- The Observations (OBS): the observations, obtained by the use of learners' tracking strategies, are the result of monitoring learner's activities and interactions with the contents and the distance learning's services. Examples of observations are: whether a user has visited a resource, the amount of time spent interacting with a given resource, etc. In general a learner's 
tracking strategy is developed in an AEHS. The information obtained by the observations can be used for the update of the user model and by the A daptation M odel.

In this paper a model for an AEHS will be proposed and original contributes in each of the previous components will be introduced. In the next paragraphs a model for the learning objects' management, a user model, an adaptation model and a tracking strategy will be described.

\section{A. The Knowledge Space: A Learning Object's M odel Proposal}

As previously said in the knowledge space of an AEHS services for the management of the educational resources by the use of descriptive information are introduced. In particular a model for the representation of the learning object is needed. In fact the opportunity of a better definition of leaning resources by the use of their didactic and pedagogical features induces to represent them with a model. In this paper the main idea is in the generation of a standardized digest of the learning object in order to better qualify and quantify it. So a vectorial representation of the learning object is proposed and the single training resource is described by a string vector so defined:

\section{Didactic Resource =\{Typology, Ontology, Pedagogi- cal_E ducational_Properties, Technical_Requisites, Rights\}}

Each component of the proposed vector is still a string vector which represents a particular aspect of resource and collects the most important information obtained combining standard description fields. The vectorial structure allows a better organization of the information related to the learning object, allowing its easier retrieval and management by the use of an AEHS. In details the descriptive vector's components can so summarized:

\{Typology\}: The main aim of this category is to furnish a global and general view of the resource. This vector contains all information useful for a general classification of the learning object. The vector $\{T y-$ pology $\}$ is so structured: $\{$ T ypology\}:= \{typology, identifier, title of the resource, author of the resource, date of creation of the resource, language, description, keywords\}

\{Ontology\}: this vector aims to contextualize the didactic context and the knowledge domain where the resource is. Thanks to this vector the AEHS can associate each resource to the course's topics or create learning object's clusters. The vector $\{0$ ntology $\}$ is so structured: \{Ontology\}: \{Purpose, Taxonpath, Taxon, Description, Keyword, Relation, Kind, Resource

\{Pedagogical_educational_properties\}: this vector allows the resource's description from a pedagogical and educative point view. The vector \{Pedagogical_educational_properties\} is so structured: \{Pedagogical educational properties\}: \{pedagogical educational properties, interactivity, resource type, interactivity level, semantic density, resource users, teaching context, age range, difficulty, learning time, description, language
\{Technical_Requisites\}: this vector describes the technical requisites that are needed for the correct resource's use. In particular, it is engaged in defining what its technological format is, what operating system makes it working, and what software is necessary to its correct utilization. In addition, it allows knowing the path where the resource is actually located. The vector \{Technical requisites\} is so structured: \{Technical_requīsites\}: \{T echnical requisites, format, size, allocātion, required software resources, required software resources in detail, duration \}

\{Rights\}: This vector describes the billing modes and the costs associated with the resource. The vector \{Rights $\}$ is so structured: $\{$ Rights\}: $=$ RRights, cost, copyright, rating

Each components previously introduced can be expressed by the use of IMS LOM fields and more in general can be obtained through the analysis of the metadata associated to the learning object. In this way the system can work with a well defined set of standard information.

\section{B. The U ser Model: a Proposal}

The runtime behaviour of an AEHS is deeply influenced by the definition of an effective user model. In particular the learner's learning characteristics influence the selection of concepts from the domain model, and so the Concept Selection Rules, as well as the selection of appropriate resources (Content Selection Rules), is required. In literature there are many definition of user model and first of all a difference between user profiling and user modelling has to be introduced. A user profile is a collection of personal information. The information is stored without adding further description or interpreting this information. User profiles represent cognitive skills, intellectual abilities, and intentions, learning styles, preferences and interactions with the system. These properties are stored after assigning them values. These values may be final or change over time. Depending on the content and the amount of information about the user, which is stored in the user profile, a user can be modelled. Thus, the user profile is used to retrieve the needed information to build up a model of the user. The model of the user is based on this information and is therefore only a small part of the real user. Nevertheless, the user model must represent the needed characteristics of the user regarding the context of the application. The behaviour of an adaptive system varies according to the data from the user model and the user profile. Without knowing anything about the user, a system would perform in exactly the same way for all users. Therefore, everywhere where an individualized response of the system is expected, a user model should be applied. Different types of applications can benefit from user models. U ser models are often components of adaptive e-learning systems and are strongly connected to the instructional part of such systems. Other applications of user modelling are for example, search engines, recommender systems or help systems. The design of the student model that we will adopt in this paper is described in [16][18] and forecasts a quintuple of features for the learner's profile. This model takes into account the learner's learning style, background knowledge and preferences by the use of the following parameters: 
- Format (f): type of media the learner prefers to study a learning resource

- Bandwidth (b): the type of link used by the learner to connect to the internet

- Interactivity (i): the level of interactivity used by the learner to interact with the learning resource

- Difficulty $(d)$ : the level of preparation of the student

- Time $(t)$ the time of study the learner spends to study a lesson

These parameters are strictly related to the IMS LIP metadata [standard and they assume values in the range $[1,10]$ coherently with the rules defined by the standard.. In this scenario an important task to accomplish is the issue of the model initialization. So at the beginning of a course or a learning's path the following questionnaires has to be submitted: the Index of Learning Style (ILS) questionnaire, an assessment questionnaire on the main topics of the course and a general questionnaire for the acquisition about generic information on the learner. The ILS questionnaire is an instrument used to assess preferences in four dimensions (active/reflective, sensing/intuitive, visual/verbal and sequential/global) of a learning style model and was designed by Richard $M$. Felder [17]. A s previously said the ILS approach furnishes information about the learning style by the use of four dimensions. The first dimension is said sensing/intuition. Sensing learners tend to like learning facts and to be patient with details and good at memorizing facts and doing hands-on (laboratory) work. Intuitive learners often prefer discovering possibilities and relationships and may be better at grasping new concepts and are often more comfortable with abstraction and mathematical formulation than sensing users. The second dimension is said active/reflective. Active learners tend to retain and understand information best by doing something active with it, discussing or applying it or explaining it to others. A ctive learners tend to like group work more than reflective learners, who prefer working alone. Reflective learners prefer to think about it quietly first. "Let's try it out and see how it works" is an active learner's phrase; "Let's think it through first" is the reflective learner's response. The third dimension is defined sequential/global. Sequential learners tend to gain understanding in linear steps, with each step following logically from the previous one. Global learners tend to learn in large jumps, absorbing material almost randomly without seeing connections, and then suddenly "getting it." The fourth dimension is defined visual/verbal. V isual learners remember best what they see - pictures, diagrams, flow charts, time lines, films, and demonstrations. Verbal learners get more out of words - written and spoken explanations. Starting from the ILS information, a matching strategy among the obtained data and some parameters defined in the IM S LIP model has been developed. In particular, from the active/reflective dimension the interactivity level of the student has been extracted. Then, from the visual/verbal dimension the type of media the learner typically uses has been extracted. In order to complete the student model, further information is necessary. In particular, it could be necessary to know which is his/her level of preparation on a particular argument, how much time he/she usually spends to study a lesson, how many times he/she usually repeats a lesson, and so on. This information cannot be obtained with only the learning style, but should be con- sidered separately. In particular the difficulty level parameter can be obtained by the use of the assessment questionnaire. This test allows the acquisition about the learner's starting competence and defines the student's starting difficulty level. While the other information, bandwidth and time of study, are collected by the use of the general questionnaire. The complete student model is so characterized:

TABLEI.

USER M ODEL

\begin{tabular}{|c|c|c|c|c|}
\hline Type of media & Interactivity level & Bandwidth & $\begin{array}{c}\text { Difficulty } \\
\text { level }\end{array}$ & Time of study \\
\hline $\begin{array}{c}\text { ILS (Visu- } \\
\text { alN } \text { erbal) }\end{array}$ & $\begin{array}{c}\text { ILS (Ac- } \\
\text { tive/Reflective) }\end{array}$ & $\begin{array}{c}\text { General } \\
\text { Questionnaire }\end{array}$ & $\begin{array}{c}\text { Assessment } \\
\text { Questionnaire }\end{array}$ & $\begin{array}{c}\text { General } \\
\text { Questionnaire }\end{array}$ \\
\hline
\end{tabular}

\section{The Observation: a Tracking Strategy Proposal}

As previously said the observation module has the aim to track and collect information during the students' learning activities. In this section the description of an approach for tracking the students during their learning activities is furnished. To this aim an effective design method for tracking the students has to take in account also the opportunity to furnish detailed information also to teachers allowing them a more efficacious evaluation and watch of student's progresses. In particular a desired tracking strategy has to capture information about the difficulties that students meet facing the various didactic units and the relative learning objects, the amount of knowledge gained during their learning path and the feedbacks needed by them. In this sense the tracking strategy is strictly relate to the adaptation model because an effective tracking strategy can furnish good information for the adaptation of the learning path. So the starting point of the proposed tracking strategy is the time which student spends when he faces a k-th Learning Object $\left(T_{k}\right)$ related in a certain topic and the final mark obtained in the evaluation test $\left(v_{k}\right)$ of the same topic. The time student $T_{k}$ is matched with a reference learning time that the docent has a priori assigned, $T^{r}{ }_{k}$, for the $k$-th Learning Object. This matching is made by using an appropriate rational function $G_{t}$. The goal of $G_{t}$ is, by setting opportunely its parameters, to give the right weight if the student has spent $a$ lot of or little time in the making use of a lesson. M oreover, the mark student $v_{k}$ is matched with the reference mark $v_{k}^{r}$. the docent has a priori assigned for that L earning O bject by using an appropriate rational function $G_{v}$. In this way, if the student has obtained a good mark, his profile is updated and the successive adapted didactic unit is located, otherwise a unit with the same content but less difficult is chosen for him (also in this case it is necessary to update the student profile). The tracking module observes the student activity during his period of a learning resource study. The two main targets of this methodology are:

- to maintain up-to-date information about student model's parameters. The information observed during learner's activity studying are:

o the studying time: this parameter evaluates the average of time used to study a learning resource and time for the first repetition.

o level of knowledge

o interest for well defined kind of media

- to provide an evaluation of the learner action related to his entire learning path by the use of information 
acquired during the observation activity. In this way it is possible to evaluate the learner performance by providing a global assessment usually based only on the final test grade.

By denoting with the subscript $u$ information related to the student and with $r$ those related to the learning resource, it is supposed to know some parameters the tutor initially sets:

- $\quad$ time of studying of his learning resource, $t_{T}$

- a time parameter $t_{x}$, generally a percentage of $t_{r}$, that measures the maximum moving from the $t_{T}$ defined by the teacher

- the fair mark $\mathrm{V}_{\mathrm{r}}$ for that learning resource.

In this way, once the student learning time, $t_{u}$ is acquired, it is possible to compare it by using the evaluation function:

$$
G_{t}=1+N+\frac{\left(T_{u}^{k}-T_{r}^{k}\right)^{2}-T_{x}^{2}}{\left(T_{u}^{k}-T_{r}^{k}\right)^{2}+\frac{T_{x}^{2}}{N}}
$$

The minimum value (i.e. 1 ) is assumed when the estimated time student corresponds with that expected, that is $t_{u} \in\left[t_{r}-t_{x}, t_{Y}+t_{x}\right]$ while the maximum value is $2+N$ where $\mathrm{N}$ is a parameter related to the difficulty of the resource. Moreover the tracking module is able to take into account how many times the student repeats the same lesson. This occurrence is considered by evaluating the function:

$$
\left.\left.\mathrm{T}_{\mathrm{k}}(\mathrm{i})=\frac{1}{1+\mathrm{a}(\mathrm{i}-1)} \in\right] 0,1\right]
$$

where $\mathrm{i}=1,2,3, \ldots$ counts the number of repetitions of the same lesson and in this way $\mathrm{T}_{\mathrm{u}}{ }^{\mathrm{K}}=\mathrm{T}^{\prime}{ }_{\mathrm{u}}{ }^{\mathrm{K}} * \mathrm{~T}_{\mathrm{K}}(\mathrm{i})$. The function has a hyperbolic progress that assumes the maximum value when $\mathrm{i}=1$ and decreases when $\mathrm{i}$ increases. The parameter a sets the decrement rate and is equal to:

$$
a=\frac{d_{u}}{2 d_{r}}
$$

In this way, if the resource is more difficult than the learner preparation level, the decrement rate does not heavily penalize the learner, and vice versa. The second target of the tracking module is providing a student evaluation by using information acquired during his studying activity. The purpose is to assess the learner performance focusing attention to his complete studying activity. To this aim, the learner assessment is a weighted average that takes into account two terms: the first is relative to the present state activity and a term relative to his past learning activity. The student assessment evaluation is then:

$$
\begin{aligned}
& \text { Score }_{k}=\propto \frac{V_{k}}{V_{\max }}\left((1-\alpha) \cdot\left(\frac{\operatorname{Sgn}\left(G_{v}\right)+1}{2}\right)+\alpha \cdot \frac{T_{k}(i)}{G_{t}} \cdot\left(\frac{1+\operatorname{Sgn}\left(D_{r}^{k}-D_{u}^{k}\right)}{2}\right)\right)+ \\
& +(1-\mu) \cdot\left(1+\frac{\log _{10}\left(S_{p}\left(Q_{k}\right)\right.}{3}\right)
\end{aligned}
$$

The first term

$$
A=\frac{V_{k}}{V_{\max }}\left((1-\alpha) \cdot\left(\frac{\operatorname{Sgn}\left(G_{v}\right)+1}{2}\right)+\alpha \cdot \frac{T_{k}(i)}{G_{t}} \cdot\left(\frac{1+\operatorname{Sgn}\left(D_{r}^{k}-D_{u}^{k}\right)}{2}\right)\right)
$$

with

$$
\mathrm{G}_{\mathrm{v}}=\mathrm{v}_{\mathrm{k}}-\mathrm{v}_{\mathrm{k}}^{\mathrm{r}} \in\left[1-\mathrm{v}_{\max }, 1+\mathrm{v}_{\max }\right] \text { and }
$$

$V_{r}^{k}=7-\left(\operatorname{Int}\left(\frac{1+\operatorname{Sgn}\left(D_{r}^{k}-3\right)}{2}\right)+\operatorname{Int}\left(\frac{1+\operatorname{Sgn}\left(D_{r}^{k}-7\right)}{2}\right)\right)$

and where $G\left(v_{k}\right)$ is a term relative to the student grade

$\mathrm{V}_{\mathrm{k}}$ obtained in the final test, represents the results obtained in the study of the last learning object.. In particular $A$ is equal to 0 when the student has a very low result and 1 when the student has a very good result. The other term $\mathrm{B}=1+\frac{\log _{10}\left(\mathrm{~S}_{\mathrm{p}}\left(\mathrm{Q}_{\mathrm{k}}\right)\right.}{3}$ takes in account the previous results of the student. In particular the term

$$
\mathrm{S}_{\mathrm{p}}\left(\mathrm{Q}_{\mathrm{k}}\right)=\frac{\mathrm{Q}_{\mathrm{k}}}{\frac{1}{\mathrm{k}-1} \sum_{\mathrm{q}=1}^{\mathrm{k}-1} \mathrm{Q}_{\mathrm{q}}} \in\left[\frac{1}{\mathrm{~V}_{\max } \mathrm{D}_{\max }^{2}}, \mathrm{~V}_{\max } \mathrm{D}_{\max }^{2}\right]
$$

where

$Q_{k}=v_{k} \frac{D_{r}^{k}}{D_{u}^{k}} \in\left[\frac{v_{\text {max }}}{D_{\text {max }}}, v_{\text {max }} D_{\text {max }}\right]$ measures the grade obtained for the actual learning object with the grades obtained in the past. The value $\mu$ is a weight which emphasizes the $A$ or the $B$ term. In general we fixed $\mu$ to the value 0,8 in order to give more importance to the last result obtained by the learner. So the score value assumes the following form:

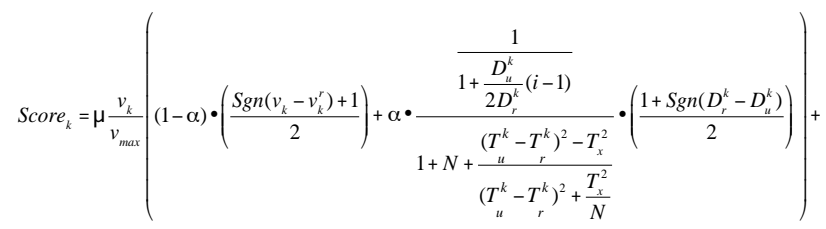

$+(1-\mu) \cdot\left(1+\log _{10}\left(\frac{v_{k} \frac{D_{r}^{k}}{D_{u}^{k}}}{\frac{1}{3} \frac{1}{k-1} \sum_{q=1}^{k-1} v_{q} \frac{D_{r}^{q}}{D_{u}^{q}}}\right)\right)$

By analyzing each single element of the Score $\mathrm{k}_{\mathrm{k}}$ term, we can realize that if Score $_{k}$ assumes a low value, learner assessment is not fair, and the learner is forced to repeat the same lesson. Otherwise, score value near to 1 he can approach to the following learning resource. In any case, the student profile parameters are updated. In particular if the learner has a preparation level greater than the k-th learning resource's difficulty one, his score assessment is not fair and his failures the final test twice, his preparation level is decreased. If the threshold for the score function is 0,5 we cans say that:

$D_{u}^{k+1}=\tilde{D}_{u}^{k} \cdot \frac{\left(1-\operatorname{Sgn}\left(\tilde{S} \operatorname{core}_{k}-\operatorname{Score}^{\text {thre }}\right)\right)}{2}+\tilde{D}_{r}^{k} \cdot \frac{\left(1+\operatorname{Sgn}\left(\tilde{S c o r e}_{k}-\text { Score }^{\text {thre }}\right)\right)}{2}$ and if

$$
\tilde{S}_{\text {core }}>\text { Score }{ }^{\text {thre }} \Rightarrow D_{u}^{k+1}=\tilde{D}_{r}^{k}=\frac{1}{k} \sum_{i=1}^{k} D_{r}^{i}
$$

Otherwise

$$
\text { Score }_{k}<\text { Score }^{\text {thre }} \Rightarrow D_{u}^{k+1}=\tilde{D}_{u}^{k}=\frac{1}{k} \sum_{i=1}^{k} D_{u}^{i}
$$


In the same way the learner’s learning time is so updated:

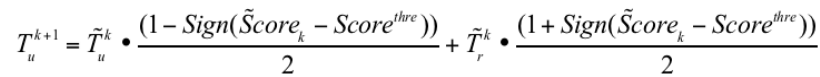
and if

$$
\text { Score }_{k}>\text { Score }{ }^{\text {thre }} \Rightarrow T_{u}^{k+1}=\tilde{T}_{r}^{k}=\frac{1}{k} \sum_{i=1}^{k} T_{r}^{i}
$$

Otherwise

$$
\tilde{\text { Score }}_{\mathrm{k}}<\text { Score }^{\text {thre }} \Rightarrow \mathrm{T}_{\mathrm{u}}^{\mathrm{k}+1}=\tilde{\mathrm{T}}_{\mathrm{u}}^{\mathrm{k}}=\frac{1}{\mathrm{k}} \sum_{\mathrm{i}=1}^{\mathrm{k}} \mathrm{T}_{\mathrm{u}}^{\mathrm{i}}
$$

Once the learner has completed the k-th learning resource, the Score $\mathrm{k}_{\mathrm{k}}$ is evaluated, and so, at the end of the learning path, the complete learner assessment can be evaluated:

$$
\text { Score }_{\mathrm{k}}=\frac{1}{\mathrm{k}} \sum_{\mathrm{i}=1}^{\mathrm{k}} \text { Score }
$$

The information updated in the IMS-LIP metadata fields are showed in table II.

TABLE II.

\begin{tabular}{|c|c|}
\hline Learner metadata fields & Semantic \\
\hline $\begin{array}{l}\text { Activity.evaluation.result.result[i]. fieldata = } \\
\text { Score }\end{array}$ & $\begin{array}{l}\text { Assessment value relative } \\
\text { to the j-th learning resource }\end{array}$ \\
\hline Activity.evaluation.result.score $=$ Score & $\begin{array}{c}\text { Assessment value relative } \\
\text { to the complete learning } \\
\text { path }\end{array}$ \\
\hline Goal.status = completed & $\begin{array}{c}\text { Overcoming relative to a } \\
\text { learning resource }\end{array}$ \\
\hline
\end{tabular}

IMS-LIP METADATA FIELDS UPDATING RELATED TO THE ASSESSMENT INFORMATION

\section{The Adaptation M odel}

In [6] two distinct areas of adaptation are distinguished: content level adaptation or adaptive presentation and link level adaptation or adaptive navigation support. This paper is focused on the design of an adaptive presentation model by starting on learner's and learning resource's information profile. In particular, the proposed model is developed in three main steps:

Step 1: evaluation of functions for the matching between student and learning profile

These functions aim to match the learners' parameters with the relative learning objects description parameters. The proposed functions express the minimum value when there is the best matching for the considered parameter, otherwise the resource parameter is far from learner. The functions are:

Interactivity: $M_{1}=1+\left|I_{r}-I_{u}\right| \in[1,10]$

Difficulty: $M_{D}=1+\left|D_{r}-D_{u}\right| \in[1,10]$

Type_of_M edia:

$$
\mathrm{M}_{\mathrm{F}}=1+\left|\mathrm{F}_{\mathrm{r}}-\mathrm{F}_{\mathrm{u}}\right| \in[1,10]
$$

Time_of_Studying: $\quad M_{T}\left(T_{r}, T_{u}\right)=11+\operatorname{Int}\left(\frac{\left(T_{r}-T_{u}\right)^{2}-10^{2}}{\left(T_{r}-T_{u}\right)^{2}+10}\right) \in[1,10]$

Bandwidth: $M_{B}=5\left(1-\operatorname{Sign}\left(B_{u}-B_{r}+2\right)\right) \in[0,10]$

Step 2: Evaluation of similarity functions

Once the matching functions are evaluated, the educational $\mathrm{C}_{\mathrm{e}}$ and $\mathrm{C}_{\mathrm{t}}$ technical similarity functions can be considered. To this end a normalized weighted average mechanism is considered:

$$
\begin{aligned}
& C_{t}=\sqrt{M_{F}\left(F_{r}, F_{u}\right)^{2}+M_{B}\left(B_{r}, B_{u}\right)^{2}} \in[1,10 \sqrt{2}] \\
& C_{e}=\sqrt{M_{T}\left(T_{r}, T_{u}\right)^{2}+M_{D}\left(D_{r}, D_{u}\right)^{2}+M_{1}\left(I_{r}, I_{u}\right)^{2}} \in[\sqrt{3}, 10 \sqrt{3}]
\end{aligned}
$$

These functions express the closeness of the resources to user profile both from the point of view of technical parameters both from the point of view of educational parameters.

\section{Step 3: Evaluation of the global matching index}

The final step is the evaluation of the distance between the learner and the learning resources in term of educational and technical characteristics. To this aim, the global index Ind is so calculated:

$$
\text { Ind }=\sqrt{C_{t}^{2}+C_{e}^{2}} \in[2,10 \sqrt{5}]
$$

In this way, the minimum value of Ind defines the nearest learning resource to the learner characteristics, namely:

$$
\operatorname{Ind}_{\mathrm{OPT}}=\operatorname{Min}_{\mathrm{i}} \mathrm{Ind}_{\mathrm{i}}
$$

In this way the AEHS works as depicted in figure 1:

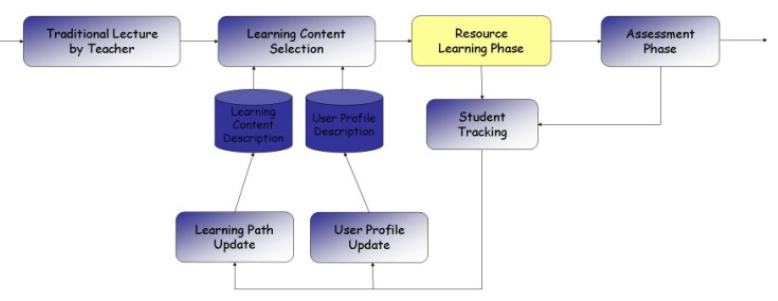

Figure 1. the proposed AEHS working cycle

\section{EXPERIMENTAL RESULTS}

In our experimentation we have considered three different blended courses Introduction to Computer Science (about 400 students), Computer Networks (about 80 students) and Software Technology for the Web (about 50 students) belonging to the faculty of Engineering and a comparison with traditional approach was conducted. For each of this course we used a dataset composed by one 
PAPER

E-LEARNing AND PERSONALIZED LEARNing PATH: A PROPOSAl BASED ON THE AdAPTIVE EdUCATIONAL...

TABLE III

OBTAINED RESULTS

\begin{tabular}{|c|c|c|c|c|c|c|}
\hline & $\begin{array}{c}\text { Introduction to } \\
\text { Computer Science } \\
\mathbf{2 0 1 1}\end{array}$ & $\begin{array}{c}\text { Introduction to } \\
\text { Computer Science } \\
\mathbf{2 0 1 2}\end{array}$ & $\begin{array}{c}\text { Computer Net- } \\
\text { works 2011 }\end{array}$ & $\begin{array}{c}\text { Computer Net- } \\
\text { works 20012 }\end{array}$ & $\begin{array}{c}\text { Software Technol- } \\
\text { ogy for the W eb } \\
\mathbf{2 0 1 0}\end{array}$ & $\begin{array}{c}\text { Software Technol- } \\
\text { ogy for the W eb } \\
\mathbf{2 0 1 1}\end{array}$ \\
\hline $\begin{array}{c}\text { Starting } \\
\text { Knowledge Level }\end{array}$ & 3,2 & 3,0 & 4,6 & 4,9 & 3,8 & 3,4 \\
\hline $\begin{array}{c}\text { Final Knowledge } \\
\text { L evel }\end{array}$ & 7,2 & 7,9 & 8,0 & 9,6 & 6,6 & 8,9 \\
\hline Increase & 4 & 4,9 & 3,4 & 4,7 & 2,8 & 5,5 \\
\hline
\end{tabular}

hundred descriptions, according the model previously described, of learning objects that the teachers created or retrieved in internet. Obviously the learning objects belong to various modules according to the ontology model described by teacher. At the same time teachers described the profile of their classes. The proposed AEHS was introduce, as plug-in, in the E-Learning Platform named Moodle. At this point we started the courses and the end of each learning object we submitted an evaluation test. In particular the course model was the following: traditional lessons and support by the use of modified Moodle platform. At the end of the courses we measured the average knowledge level of students. At the same time we compared the values with the other ones obtained in the previous year in the same courses. In particular the courses used the same datasets and a course model based on traditional lessons and by the use of a normal Moodle platform. The obtained results are depicted in table III.

In particular the figure 2 expresses the average knowledge level gained by the students during the learning activities is expressed. As we can see the obtained results show as the proposed approach increase the students' knowledge level.

\section{CONCLUSIONS}

In this paper we showed an AEHS based on the definition of a set of features related to the concepts, skills and attitudes the student is expected to assimilate by the end of a unit. Each feature is represented by means of appropriate mathematical functions, which are combined in a mathematical model devised to facilitate the course characterization and comparison and to provide support for diagnostics. In the paper we showed the design and implementation of a software module for deducing the representative "vector" of a given student starting from the standard description of various resources (student profiles, content descriptions and so on). We discussed experimental results in using the quoted vectors to find the most suitable set of contents for each student profile and we proved its effectiveness in some real cases.

\section{REFERENCES}

[1] N., Henze, W., Nejdl, "A Logical Characterization of Adaptive Educational Hypermedia”, New Review of Hypermedia and Multimedia (NRHM), 10(1), 77-113, 2004 http://dx.doi.org/10.1080/ 13614560410001728128

[2] Curtis A. Carver Jr, J. M.D. Hill, Udo W. Pooch, "Third Generation Adaptive Hypermedia Systems”, Proceedings of WebNet World Conference on the WWW and Internet 1999 (pp. 177-182). Chesapeake, VA: AACE, 1999

[3] P. Brusilovsky, "Intelligent Tutor, Environment and Manual for Introductory Programming”, Educational and Training Technology International, 29(1): 26-34, 1992 http://dx.doi.org/10.1080/ 0954730920290104
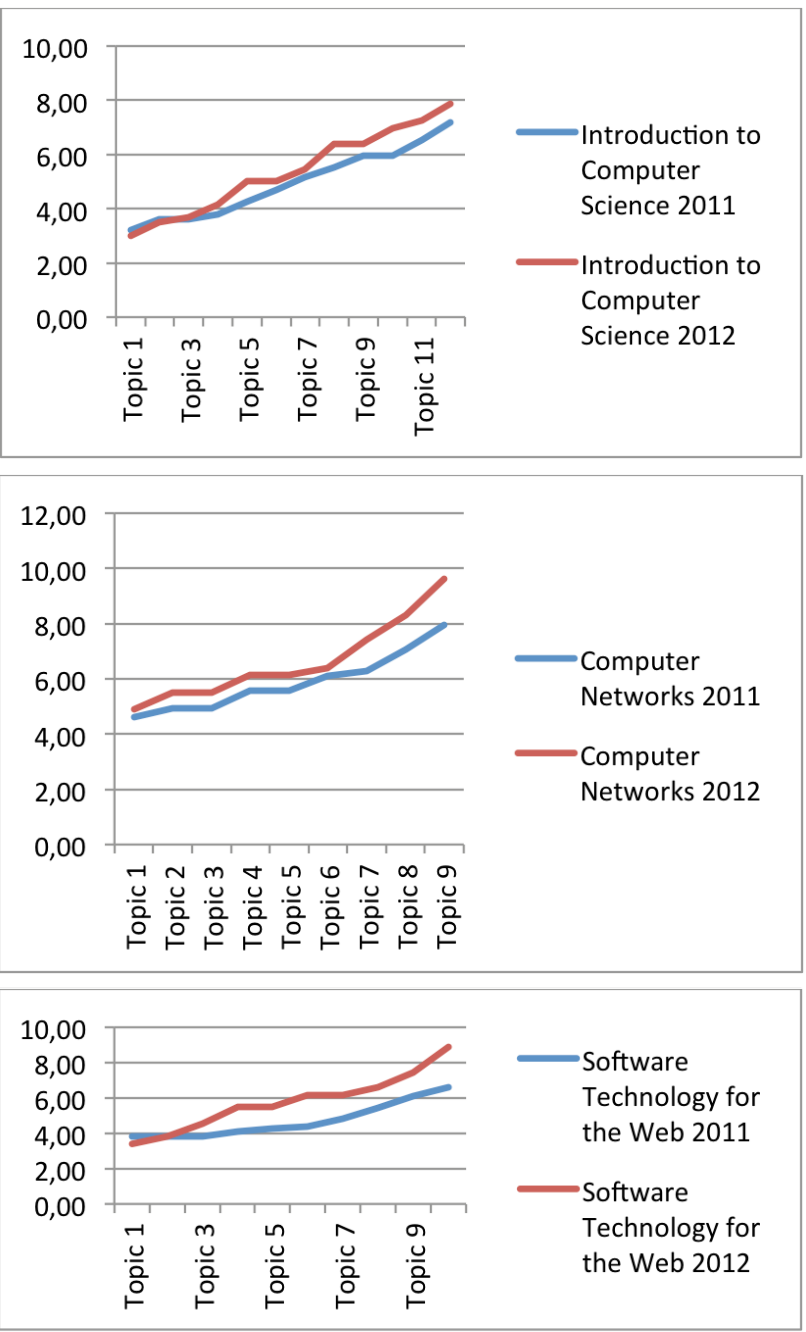

Figure 2. Average learning knowledge expressed by the classrooms during the various learning activities

[4] C. Boyle, A.O. Encarnacion, "Multimedia Intelligent Documentation: Metadoc V., 11th annual international conference on systems documentation, Kitchener, pp. 21-27, 1993

[5] H.D. Bocker, H. Hohl, T. Schwab, "Hypadapter Individualizing Hypertext“, Interact 90, pp. 931-936, 1990

[6] P.D. Bra, L. Calvi, “AHA: a Generic Adaptive Hypermedia System”, second workshop on Adaptive Hypertext and Hypermedia, pp. 5-12, 1998

[7] P. Brusilovsky, J. Eklund, “A Study of User Model Based Link Annotation in Educational Hypermedia", Journal of Universal Computer Science, 4(4), pp. 429-448, 1998

[8] L. Zaitseva, C. Boule, "Student Models in Computer-Based Education", Proceedings of the third IEEE International Conference on Advanced Learning Technologies, 2003, 674-676 http://dx.doi.org/10.1109/ICALT.2003.1215174 
PAPER

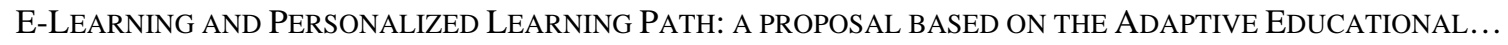

[9] M. Specht, A. Zimmermann, “An Architecture for Contextualized Learning Experiences”, Proceedings of the sixth IEEE International Conference on Advanced Learning Technologies, 2006, 169-173 http://dx.doi.org/10.1109/ICALT.2006.1652397

[10] J. E. Greer, T. Philip, “Guided Navigation Through Hyperspace ”, Workshop Intelligent Educational Systems on the Word Wide Web, 1997

[11] J. R. Thomson, J. Cooke, J. E. Greer, “The MicroWeb toolkit: Bringing the WWW to the Studentroom”, Proceedings of WebNet 96 - World Conference of the Web Society San Francisco, 1996

[12] P. Brusilovsky, “Adaptive hypermedia. Methods and techniques of adaptive hypermedia”, International Journal of User Modeling and User-Adapted Interaction, 11 (1/2), 87-110, 2001 http://dx.doi.org/10.1023/A:1011143116306

[13] Yi Shang, Hongchi Shi, Su-Shing Chen, “An Intelligent Distributed Environment for Active Learning”, Journal on Educational Resources in Computing (JERIC), 1, 4, 2001 http://dx.doi.org/10.1145/384055.384059

[14] P. De Bra, L. Aroyo, A. Cristea, “Adaptive Web-based Educational Hypermedia”, In Levene, M. \& Poulovassilis, A. (Eds.), Web Dynamics, Adaptive to Change in Content, Size, Topology and Use, Heidelberg, Germany: Springer, 387-410, 2004

[15] N. Henze, W. Nejdl, “A Logical Characterization of Adaptive Educational Hypermedia”, New Review of Hypermedia and Multimedia (NRHM), 10 (1), 77-113, 2004 http://dx.doi.org/10.1080/ $\underline{13614560410001728128}$
[16] Colace, F., De Santo, M. \& Vento, M. (2005). Personalized Learning Path Based on Metadata Standards. International Journal on ELearning. 4 (3), pp. 317-335. Norfolk, VA: AACE, 2003

[17] R. M. Felder, J. Spurlin, J, “Applications, reliability and validity of the Index of Learning Styles”, International Journal of Engineering Education, 21(1), 2001

[18] F. Colace, M. De Santo, Ontology for E-Learning: A Bayesian Approach. IEEE Trans. Education 53(2): 223-233, 2010 http://dx.doi.org/10.1109/TE.2009.2012537

\section{AUTHORS}

Francesco Colace is with the DIEM - Università degli Studi di Salerno, Fisciano, SA 84084 Via Papa Giovanni Paolo II 132, Italy, (fcolace@unisa.it).

M assimo De Santo is with the DIEM - Università degli Studi di Salerno, Fisciano, SA 84084 Via Papa Giovanni Paolo II 132, Italy, (desanto@unisa.it).

L uca G reco is with the DIEM - Università degli Studi di Salerno, Fisciano, SA 84084 Via Papa Giovanni Paolo II 132, Italy, (lgreco@unisa.it).

This article is an extended and modified version of a paper presented at the 2013 IEEE International Conference on Teaching, Assessment and Learning for Engineering (TALE2013), held 26-29 August 2013, Bali Dynasty Resort, Kuta, Indonesia. Submitted 27 September 2013. Published as re-submitted by the authors 20 March 2014. 